\title{
Performance of Jatropha biodiesel production and its environmental and socio-economic impacts - A case study in Southern India
}

\author{
Lisa Axelsson ${ }^{1}$, Maria Franzén ${ }^{1}$, Madelene Ostwald ${ }^{1,2, *}$, Göran Berndes ${ }^{1}$, N.H. Ravindranath ${ }^{3}$ \\ ${ }^{1}$ Physical Resource Theory, Department of Energy and Environment, Chalmers University of Technology, \\ Göteborg, Sweden \\ ${ }^{2}$ Centre for Climate Science and Policy Research, Department of Water and Environmental Studies, Linköping \\ University, Norrköping, Sweden \\ ${ }^{3}$ Centre for Sustainable Technologies \& Centre for Ecological Science, Indian Institute of Science, Bangalore, \\ India \\ *Corresponding author. Tel: +46 11363292, Fax: +46 11363292,Email: madelene.ostwald@liu.se
}

\begin{abstract}
In India expectations have been high on production of biodiesel from the oil-crop Jatropha. Jatropha is promoted as a drought- and pest-resistant crop, with the potential to grow on degraded soil with a low amount of inputs. These characteristics encourage hope for positive environmental and socio-economic impacts from Jatropha biodiesel production. The purpose of this study was to explore the performance of Jatropha biodiesel production in Southern India, to identify motivational factors for continued Jatropha cultivation, and to assess environmental and socio-economic impacts of the Jatropha biodiesel production. 106 farmers who have or have had Jatropha plantations were visited and interviewed regarding their opinion of Jatropha cultivation. The result indicates that 85 percent of the farmers have discontinued cultivation of Jatropha. The main barriers to continued cultivation derive from ecological problems, economic losses, and problems in the development and execution of the governmental implementation of the Jatropha programme. The Jatropha characteristics were overrated, and the plantations failed to provide income to the farmer. A common factor for the farmers who continued Jatropha cultivation was that they had the economic means to maintain non-profitable plantations. As the Jatropha programme was not as successful as expected, the expected positive environmental and socio-economic impacts have not been realized.
\end{abstract}

Keywords: Household interviews, Drivers and barriers, Land use, Rural development.

\section{Introduction}

Jatropha Curcas (Jatropha) has been regarded as one of the most promising crops for securing energy supply and for socio-economic development in developing countries. Jatropha is a small tree or large bush that develops fruits containing seeds with an oil content of 32 to 40 percent, which can be transformed into biodiesel [1]. Promoters of Jatropha argue that the biodiesel from Jatropha does not compete directly with food production since the whole plant is toxic and hence non-edible. More importantly, the potential of Jatropha to grow on degraded soil and its resistance to drought and pests enable cultivation on land that is not suitable for food production [2]. The characteristics of Jatropha have raised expectations for positive environmental and socio-economic impacts from biodiesel production.

India is one of the countries that have had high expectations on production of biofuels for secured energy supply and sustainable environmental and socio-economic development. In 2003 the Indian government declared a National Mission on Biofuels, to drive large-scale implementation of biofuel production. The National Mission on Biofuels stated a five percent blending target of biodiesel in conventional diesel, with a 20-percent blending target for 2012 [2]. The Planning Commission for the National Mission on Biofuels announced that Jatropha was found to be the most suitable biodiesel crop for the stated energy, environmental, and socio-economic purpose, and initiated a programme for Jatropha implementation [3]. The Planning Commission estimated land areas needed to achieve the blending target and identified land areas available and suitable for Jatropha cultivation. 


\section{Description of the study and methodology}

This study was performed during the spring of 2010 with the purpose to explore the performance of Jatropha biodiesel production under prevailing energy and agricultural conditions in Southern India. The focus was to identify motivational factors for continuation and termination of Jatropha cultivation and to assess environmental and socio-economic impacts of the Jatropha biodiesel production.

To address the purpose, semi-structured interviews with farmers in the states Andhra Pradesh and Tamil Nadu who have or have had Jatropha plantations were performed with the aid of a translator. Questions regarding the socio-economic situation of the farmers, the performance of their Jatropha plantations, and their reasons for continuing/discontinuing cultivation were asked. Farmers targeted for participation in this study were respondents from a field study performed in 2005-06 by researchers from the Indian Institute of Science in Bangalore which focused on gaining knowledge on the performance of Jatropha plantations in Southern India and the socio-economic status of the Jatropha farmers. Additional farmers were added to the sample during the process to get a more complete picture of Jatropha cultivation within the two states.

The total number of respondents was 106 (77 in Andhra Pradesh, 29 in Tamil Nadu), where 54 were a part of the previous study. A distinction was made between the respondents depending on the ownership of their land, dividing them into three groups; private farmers, community land, and industry/research land. The majority of the respondents were private farmers, having ownership rights to their land or having land assigned specifically to them by the government to sustain their livelihood. Apart from the interview respondents government officials, scientific researchers, and other concerned actors contributed to understanding of the subject through informal discussions.

Three limitations made within the study need to be acknowledged. Geographically the field study was limited to the two states Andhra Pradesh and Tamil Nadu. Regarding the exploration of the performance of Jatropha biodiesel production the study mainly focused on the cultivation stage, since the production process in the studied districts had often not reached further stages. When analysing the results private farmers have been in focus due to that one of the objectives of the study was to assess the socio-economic impacts of Jatropha cultivation.

\section{Results}

The results of the field study provide information on the performance of Jatropha cultivation, and information on socio-economic status of Jatropha farmers was needed for understanding and further interpretation of the results. For knowledge on socio-economic status the private farmers were asked basic questions regarding landholdings, size of household, occupation and education level. The results indicate that Jatropha farmers commonly have small landholdings and low level of education, and that the economic situation is stronger among Jatropha farmers in Tamil Nadu than in Andhra Pradesh.

\subsection{Implementation of Jatropha}

The initiation of large-scale Jatropha cultivation was driven by the government through national and state government agencies, and within the states the different district governments were encouraged to design and initiate implementation programmes for Jatropha plantation. The National Mission on Biofuels stated that investments in the implementation of 
biodiesel production should have been made by the government, for example by using already existing poverty alleviation programmes.

The implementation in the studied districts was driven mainly by agricultural and rural departments of the government, but in some cases also by local NGOs and private companies. A majority of the respondents, 74 percent in Andhra Pradesh (57 of 77 respondents) and 90 percent in Tamil Nadu (26 of 29 respondents), state that the idea of initiating Jatropha plantations came from a government agency.

To promote plantation of Jatropha to farmers the local governments announced incentives in the form of free Jatropha seedlings, financial subsidies, subsidised agricultural facilities, bank loans and promises of future income from the plantations. The involved farmers were also promised information and training in cultivation practices.

\subsection{Continuation and termination}

The field study shows that a majority of the interviewed farmers discontinued cultivation of Jatropha; 85 percent of the farmers (90 of 106 respondents) discontinued cultivation and 15 percent (16 of 106 respondents) continued, with or without maintenance of the plantations (see Fig. 1).

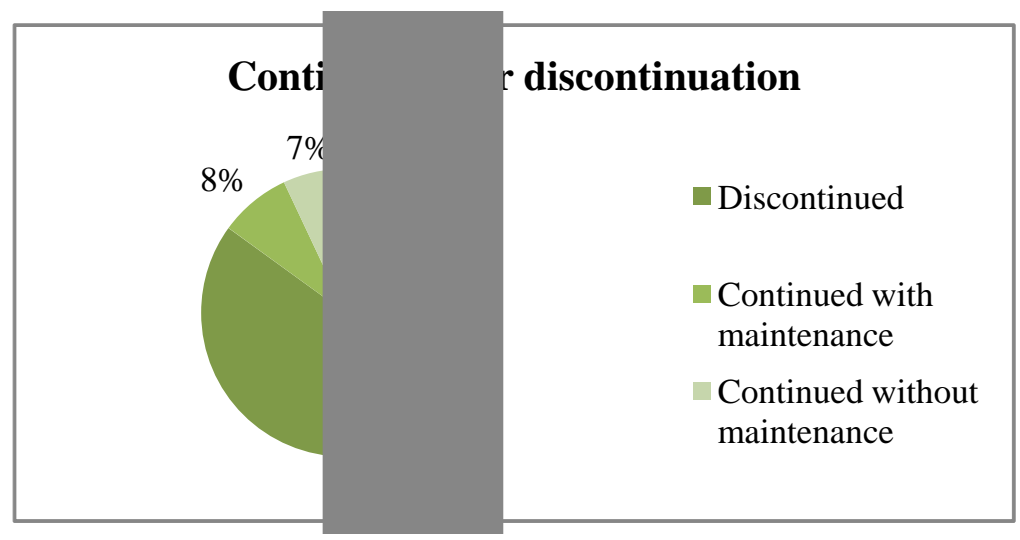

Fig. 1. Percentage of the total number of respondents who have discontinued or continued (with or without maintenance) cultivation of Jatropha.

\subsection{Drivers}

The field study shows that only 15 percent of the interviewed farmers (16 of 106 respondents) have continued cultivation of Jatropha. Of the continuing 16 respondents nine have continued with maintenance of their plantations and the other seven respondents have stopped maintaining their plantations but have not removed the plants in order to use the land for other purposes. Reasons mentioned for keeping plantations or parts of plantations without maintenance and with no expectation on outcome are costs for removal of the plants and not having any plans for alternative uses for the land. 
Drivers to continued Jatropha cultivation mentioned by the farmers were divided into three categories: economic, ecological and implementation (see Fig. 2). Drivers mentioned were hope for future economic possibilities, that the Jatropha plants have a positive effect on other plants, that the plants have survived even if the plantations are not maintained and that the plantations were implemented and kept for demonstration purposes. Each farmer could mention more than one driver.

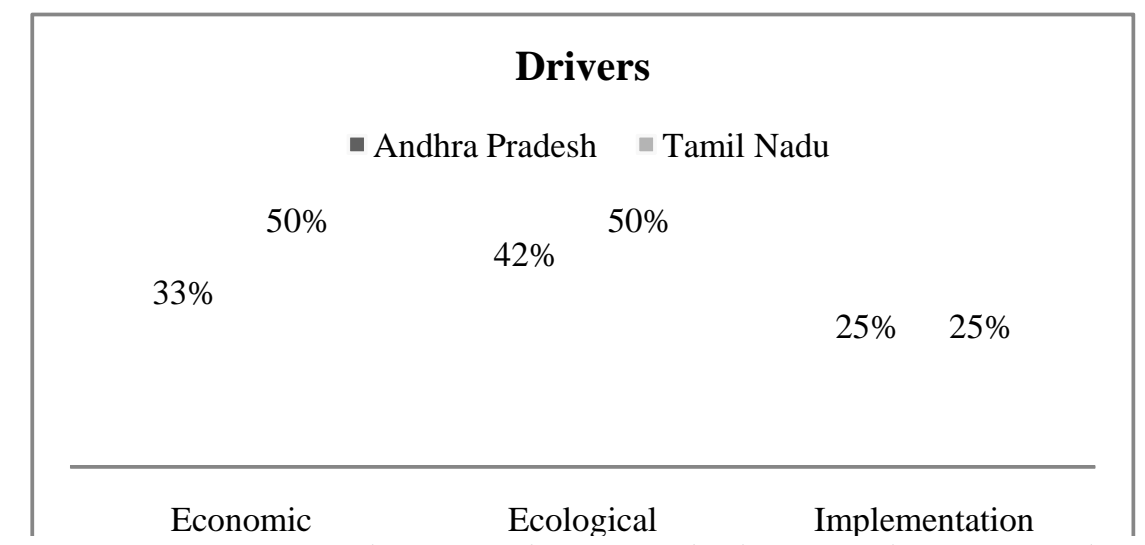

Fig. 2. Percentage of the respondents from both states who mentioned drivers within each of the three categories.

The number of continuing farmers is small, they work under different agricultural and economic conditions and have a variety of reasons for keeping their plantations, and there are no clear differences between drivers mentioned by farmers in Andhra Pradesh and farmers in Tamil Nadu. Hence it is difficult to draw any general conclusions on the drivers for continued cultivation of Jatropha. What can be noted is that all farmers who have kept and maintained their plantations have the economic means to maintain non-profitable plantations. In the case of private farmers or companies who have continued they all have other sources of income and incomes from Jatropha are considered additional. Where non-private actors have continued cultivation, the plantations are undertaken and continued for the purpose of demonstration or research and are not privately funded.

\subsection{Barriers}

The main reason for choosing Jatropha for the large-scale programme for biofuel production was its agricultural characteristics: the suitability for cultivation on barren and fallow land, the low demand for inputs, and the resistance to pests and drought. Experiences from plantations clearly show that Jatropha production has not been able to meet the high expectations, 85 percent of the interviewed farmers (90 of 106 respondents) have discontinued cultivation of Jatropha.

The farmers were asked about their reasons for not continuing cultivation of Jatropha and mentioned a wide range of barriers to cultivation. These barriers were divided into five main categories: economic, ecological, market, knowledge, and implementation, where barriers within the ecological category were most frequently mentioned (see Fig. 3). The main barriers within the ecological category are connected to problems for Jatropha to grow and yield under poor conditions; 54 percent of the respondents (57 of 106 respondents) state water scarcity and climatic problems as barriers, and 11 percent (12 of 106 respondents) mention insufficient yields. In the economic category the most mentioned barriers are insufficient income from the plantations and cost for labour. The respondents also experienced barriers derived from the implementation of the Jatropha programme; the most mentioned barriers within the 
implementation category are lack of support from the government or other actor that initiated Jatropha cultivation, and that promises made in the initial stage had not been fulfilled. Some of the reasons mentioned are closely connected, sometimes it is difficult to distinguish one single barrier since one problem mentioned may be the root of another. For example, if low or no income is mentioned as a barrier to continued cultivation, this lack of income may be due to low yields caused by water scarcity.

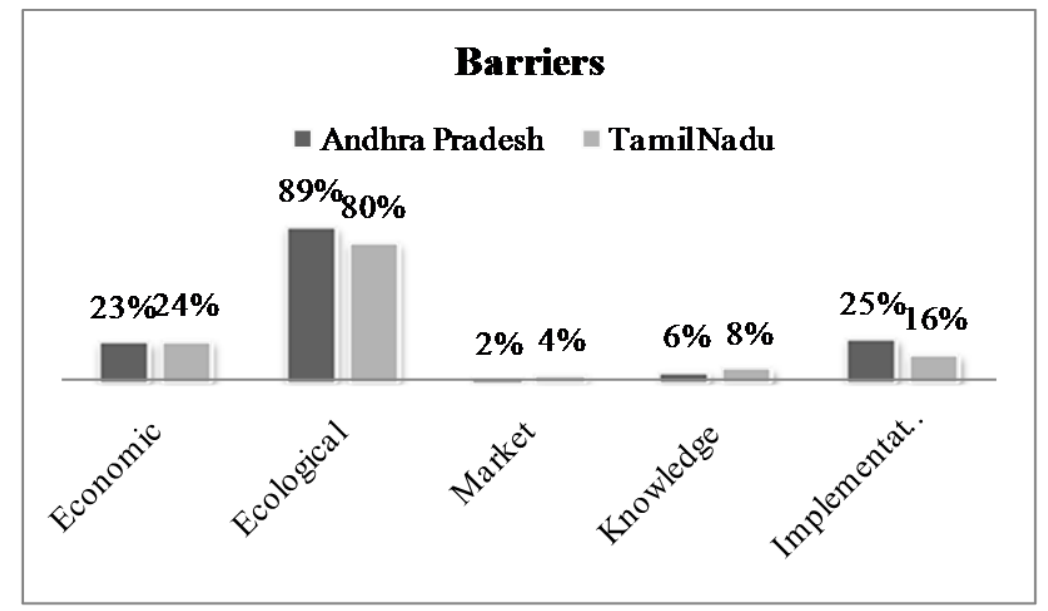

Fig. 3. Percentage of respondents from both states who mentioned barriers within each of the five categories.

\subsection{Inputs}

Jatropha was promoted as a crop that could survive and yield on barren land without inputs of water and fertilizers. Jatropha's drought resistance provided an opportunity for farmers on rainfed lands, who had been suffering from drought and had not been able to gain yields from their land. But under harsh rainfed conditions Jatropha plantations failed to yield and could often not even survive. The single largest barrier to continued cultivation of Jatropha mentioned by the interviewed farmers was water scarcity. It seems that inputs of both water and fertilizers are needed for survival of the plantations on poor soils. 70 percent of the interviewed farmers (74 of 106 respondents) mentioned that they have been using some kind of irrigation system, and 25 and 32 percent used chemical and biological fertilizers, respectively. Note that these figures do not take amount and frequency into consideration. However, even with inputs Jatropha failed to give satisfying yields.

\subsection{Insufficient yields and incomes}

One of the most important barriers to continued cultivation of Jatropha was the low or nonexisting economic returns from the plantations. In most cases there was no or very low yield, and hence no incomes from harvests to cover the cost for the plantation. 6 percent (5 of 77 respondents) in Andhra Pradesh and 55 percent of the respondents (16 of 29 respondents) in Tamil Nadu harvested seeds from their plantations. The resulting amount of dry seeds from these 21 respondents who harvested ranged from 2.5 to $2470 \mathrm{kgs} / \mathrm{ha} / \mathrm{year}$, where only two of the respondents reached more than $370 \mathrm{kgs} / \mathrm{ha} / \mathrm{year}$, while the yield suggested by district initiators ranged from 2470 to $12355 \mathrm{kgs} / \mathrm{ha} /$ year [4]. Adding to the financial problems many farmers substituted Jatropha for other crops and experienced loss of income from these crops. 


\subsection{Jatropha plantation details}

Jatropha was promoted as a plant that could be cultivated on wasteland, not suitable for cultivation of other crops, to avoid competition with food production. In Andhra Pradesh, 78 percent of the land used for Jatropha was regarded by the respondent as cropland, 17 percent was wasteland or barren land, four percent of the land was used for grazing, and one percent was considered forest land. In Tamil Nadu 93 percent of the land used for Jatropha was cropland, three percent wasteland/barren land, and three percent was used for grazing. In total, 82 percent of the interviewed farmers in the two states planted Jatropha on cropland, which was previously used to grow a variety of food crops that were removed for plantation of Jatropha. However, to consider land as cropland does not necessarily mean that the land is high-quality arable land since there are often discrepancies in what is regarded as cropland depending on who defines it.

In general the Jatropha plantations in both states were kept for a short period of time. Out of the farmers who have discontinued Jatropha cultivation no respondent have kept their plantation for more than 5 years, a majority discontinued within three years, and 33 percent already within one year. The results indicate that the respondents in Andhra Pradesh in general kept their plantations for a shorter period of time than the respondents in Tamil Nadu.

\section{Discussion}

The results from the field study have provided a picture of the performance of Jatropha cultivation and the experiences of the Jatropha farmers. However, the interviews did not always provide a clear picture of the reasons to problems experienced in the field, and further discussion is needed for understanding of these problems.

\subsection{Insufficient yields}

One of the main problems encountered during Jatropha cultivation is the failure to reach satisfying yields. To some extent the explanation can be that the expectations on Jatropha characteristics, such as drought resistance and ability to grow on degraded soils, have been too high and that cultivation under poor conditions has failed. But experiences in the studied districts show that even if inputs are applied and plantations are properly maintained the yields have not reached expected levels. The field study has failed to provide any explanation to this problem. When questioned about reasons for yields failing, neither farmers, researchers, nor government officials were able to provide clear answers. They have mentioned reasons such as unsuitability of soil and climate or poor maintenance. One theory, provided during an informal discussion with a representative of an institute involved in Jatropha research, is that cross-pollination by air has created hybrids of different Jatropha varieties that do not possess the agricultural characteristics of Jatropha Curcas. This would mean that what the farmers actually grow on their fields is not Jatropha Curcas but a variety that is not as resistant and high-yielding as the intended crop.

\subsection{Plantation life time}

When discussing failing yields, one important aspect to consider is the life time of the Jatropha plantations. Jatropha is not producing any economic yield the first three years, but most farmers have removed their plantations within three years after planting, hence before the time when economic yield could be expected. Furthermore, 33 percent of the farmers removed their Jatropha plantations within one year after planting. This may affect the total perception of yield failure, since the plantations could possibly have yielded if maintained for a longer time. However, most of these farmers cultivated Jatropha under poor conditions and 
as plantations on similar lands in the area have failed, it is uncertain if this aspect has a significant effect overall.

One explanation for the early removal is that farmers could not afford to maintain plantations without any additional sources of income. Without maintenance, the plantations were in bad condition, which made it hard to expect that a good yield would ever be reached. Another explanation may be in the guidelines for implementation of the Jatropha programme. These guidelines provided the opportunity to implement plantations under already existing poverty alleviation programmes. As a consequence, a large part of the targeted actors were poor and marginal farmers. People living in poverty are constantly in acute need of cash to sustain their livelihood, and many farmers accepted to start Jatropha plantations just to get access to the financial subsidies and loans promised in the implementation programme. The farmers received seedlings to start their plantations, but in most cases other subsidies failed to reach the farmers. Without income, poor farmers could not afford to maintain their Jatropha plantations. With government subsidies or loans it could have been possible for farmers to keep their plantations until the time economic yields could be expected. A prerequisite for this is that the farmers are aware of details regarding yield expectations and the stages of the plantation development.

\subsection{Effects of the planning and implementation of the Jatropha programme}

Many of the problems seem to root in poor planning and implementation of the national Jatropha programme. It is common practice in the studied districts to make a technical assessment and present a scientific protocol before the release of new crops to ensure compatibility with prevailing conditions. In the case of Jatropha no trials were made, instead district level authorities trusted information from the national and state level, and provided this to the farmers. If studies under prevailing conditions had been made prior to implementation, the inability to meet the expectations on Jatropha's agricultural characteristics could have been discovered and the government departments could have avoided promotion of an unsuccessful crop to the local farmers. Pre-studies could also have allowed for better-performing varieties to be developed. Better information on Jatropha and its characteristics would have enabled better extension services to the farmers, and the farmers need not have been insufficiently knowledgeable about maintenance and use.

Another problem rooting in poor implementation is lack of government support to Jatropha farmers. The National Mission on Biofuels stated that investments in the implementation of Jatropha production should be made by the government. This would be ensured by subsidies and loans to the farmers. From the interviews it is clear that the incentives promised during the implementation programme often did not reach the farmers. The majority of the farmers received free seedlings as promised. Only 39 percent of the private farmers (37 of 96 respondents) received some kind of support apart from free seedlings. Many farmers mentioned lack of government support or unfulfilled promises as barriers to continued cultivation of Jatropha.

\subsection{Land use and competition with food production}

One of the main reasons Jatropha was chosen for the biofuel programme was that it would not compete with food production. The Planning Commission identified land areas available and suitable for Jatropha plantation. The identified land areas were on land classified as wasteland, not suitable for cultivation of other crops, to avoid competition with food production. Still, 82 percent of the farmers (87 of 106 respondents) removed plantations of food crops for Jatropha, or planted it on land which is suitable for other crops. One reason for 
this could be a gap in perception of what is considered wasteland; the government targeted farmers on land they classified as wasteland, while the farmers viewed it as cropland. The reason could also be that economic incentives, promises of higher incomes and pressure from the district authorities pushed farmers to substitute Jatropha for their food crops. The district authorities may have been influenced to implement Jatropha on cropland due to lack of information on the National Mission on Biofuels and pressure for fast implementation from national and state governments. In 2008, the Indian government announced a new biofuel policy that further emphasized some of the issues that were criticised in the National Mission on Biofuels, among these the competition with food production.

\section{Conclusions}

85 percent of the interviewed farmers have discontinued cultivation of Jatropha due to poor performance. Jatropha biodiesel production was advocated based on the idea that Jatropha could be cultivated on degraded or barren land, that demand for inputs was low, and that the crop was resistant to drought and pests. Experiences in the field show that Jatropha has failed to survive and/or grow on poor soils and that a majority of the farmers planted Jatropha on cropland. The plantations have not been able to tolerate drought as well as expected, and pest attacks have occurred in several cases. Farmers have experienced that the crop requires inputs for survival and growth and have used irrigation, fertilizers, manure, and pesticides. Even when planted on fertile land and provided inputs, Jatropha did not produce a sufficient yield. Problems experienced in the field can be related to the planning and implementation of the Jatropha programme where a major problem is that the implementation was not preceded by studies of cultivation under prevailing conditions. A major problem experienced by the farmers is that they have not received subsidies and other support that was promised during the implementation process.

The Jatropha programme was expected to have positive socio-economic and environmental impacts. However, 82 percent of the farmers planted Jatropha on cropland, which entailed competition with food production. Instead of gaining additional income from Jatropha plantations, farmers experienced financial losses and reduced income. Further, as only small amounts of Jatropha biodiesel was produced, the positive impacts on environment and energy security was not realized.

In Southern India there is still on-going research on Jatropha and hope for Jatropha biodiesel production, but more scientific knowledge on Jatropha characteristics is needed, and development of high-yielding and resistant varieties is required, for Jatropha to become a successful biodiesel crop.

\section{References}

[1] W. M. J. Achten, L.Verchot, E. Franken, Y. J. Mathijs, V. P Singh, R. Aerts, B. Muys, Jatropha bio-diesel production and use, Biomass and Bioenergy 32, 2008, pp. 1063-1084

[2] P. K. Biswas, S. Pohit, R. Kumar, Biodiesel from jatropha: Can India meet the 20\% blending target? Energy Policy, article in press.

[3] Ministry of New \& Renewable Energy, Government of India, National Policy on Biofuels, 2008 (http://www.svlele.com/nbp.pdf)

[4] DWMA - District Water Management Agency (2005) Annual Action Plans 2005-06. http://www.rd.ap.gov.in/CRDAction\%20plans/actionplans/Kadapa.htm (2010.05.21) 